\title{
Relationship of Gender and Treatment Long with Quality of Life of Pulmonary Tuberculosis Patients in Oesapa Public Health Center, Kupang City
}

\author{
Yelsi Amaral Menina Dore ${ }^{1^{*}}$, Maria Agnes ED ${ }^{2}$, Jojor Sihotang
}

\author{
${ }^{1}$ Faculty of Medicine, University of Nusa Cendana \\ ${ }^{2}$ Department of Public Health, Faculty of Medicine, University of Nusa Cendana \\ ${ }^{3}$ Department of Obstetrics and Gynecology and Gynecology Faculty of Medicine, University of Nusa Cendana
}

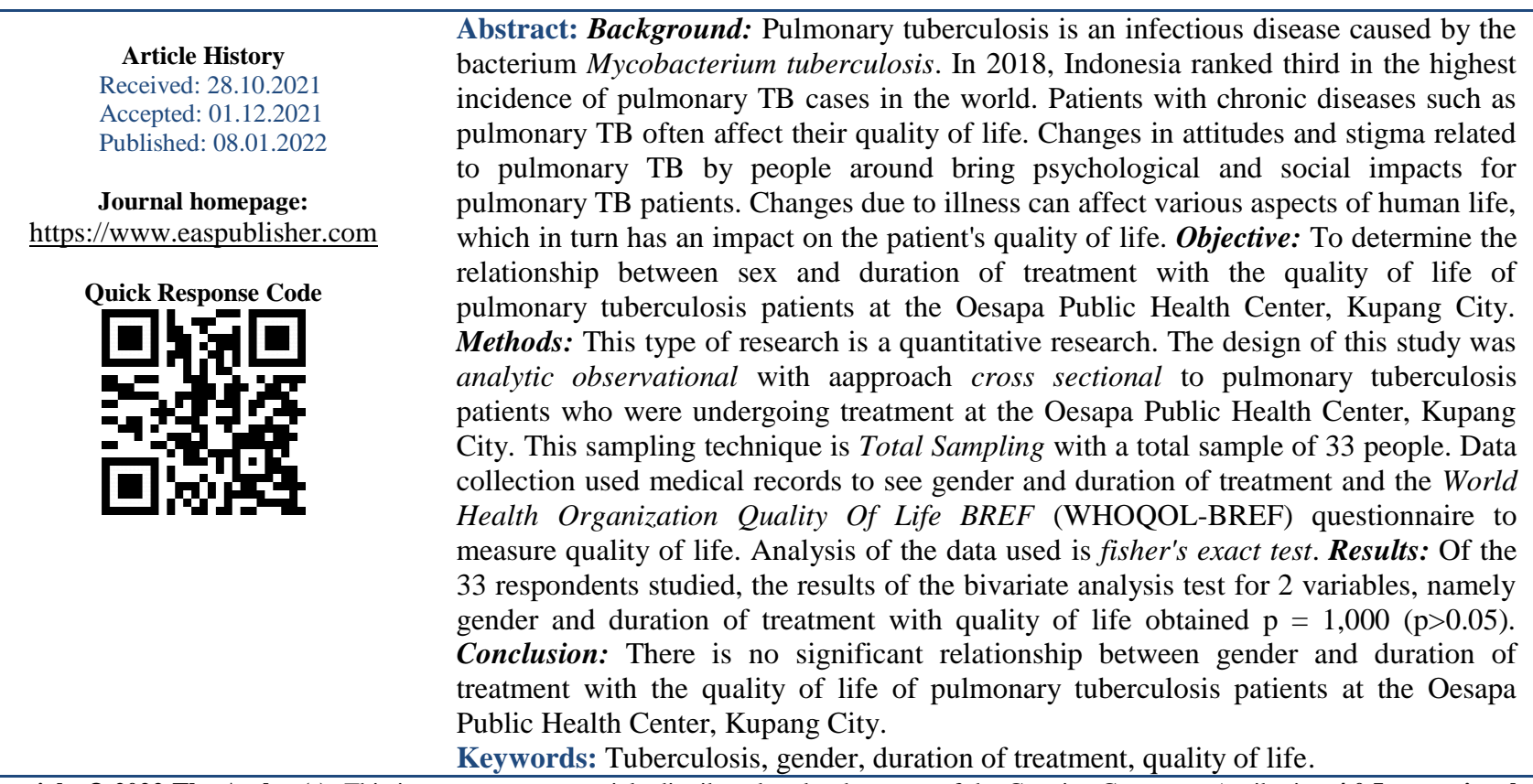

Copyright (C) 2022 The Author(s): This is an open-access article distributed under the terms of the Creative Commons Attribution 4.0 International License (CC BY-NC 4.0) which permits unrestricted use, distribution, and reproduction in any medium for non-commercial use provided the original author and source are credited.

\section{INTRODUCTION}

Pulmonary tuberculosis (TB) is a disease that requires a long treatment time and requires a lot of drugs to be consumed [1]. Data from the World Health Organization (WHO) states that, globally, TB is one of the 10 main causes of death so that currently TB is still a top priority in the world and is one of the goals in the Sustainability Development Goals (SDGs) where the target is to solve TB cases. by $2030[2,3]$.

In 2017, Kupang City occupies the highest position with the total number of TB cases as many as 739 with a finding rate of 13.98 per 100,000 population and 359 cases for pulmonary TB new cases of smear positive and in 2018 increased to 669 cases [4]. The highest incidence of pulmonary TB in Kupang City is in several sub-districts, one of which is Kelapa Lima District which is the primary service area of the Oesapa Health Center [5]. Based on data from the Kupang City Health Office in 2017, the number of pulmonary TB patients at the Oesapa Health Center was 120 cases, in 2018 there were 104 cases and in 2019 there were 101 cases. This high prevalence of pulmonary TB cases is also related to the quality of life of pulmonary TB patients. It was found that almost all pulmonary TB patients had a poor quality of life.

Quality of life is influenced by several factors including gender and duration of treatment. Based on gender, AFB (+) cases in men were higher than women, which was almost 1.5 times compared to AFB $(+)$ cases in women. Fadda and Jiron said that men and women have differences in the roles and access and control of 
various sources so that the needs or things that are important for men and women will also be different. This indicates that there are differences in aspects of life in relation to the quality of life for men and women [6]. Based on the recommendations from WHO, the duration of effective and therapeutic pulmonary TB treatment takes 6-8 months without any negligence during treatment. The duration of the treatment, many patients with pulmonary TB experience symptoms of stress, loss of motivation, life goals that lead to loss of quality of life [7].

\section{RESEARCH METHODS}

This research is an observational analytic study using aresearch design cross sectional which aims to determine the relationship betwee gender and duration of treatment with the quality of life of pulmonary tuberculosis patients at the Oesapa Public Health Center, Kupang City.

This research was conducted at the Oesapa Public Health Center in Kupang City on pulmonary tuberculosis patients from January to November with a total of 61 people. The time of the study was carried out in November 2020.

Data related to gender and duration of treatment were obtained from the medical records of the puskesmas while the assessment of the quality of life of respondents was carried out using the WHOQOL-BREF questionnaire.

The sampling technique in this study used total sampling with a total sample of 33 people who met the inclusion criteria. The research was analyzed by univariate and bivariate using Fisher's exact test.

The independent variables in this study were gender and duration of treatment while the dependent variable in this study was the quality of life of pulmonary tuberculosis patients.

\section{RESULTS}

\section{Characteristics of Respondents}

This study took 33 samples who had met the inclusion criteria, which were obtained from the number of pulmonary TB patients in January - November totaling 61 people. During the study, 28 people were excluded because they had finished treatment.

In this study, data were taken about the characteristics of the respondents which included age, education level, occupation and marital status.

Statistically the characteristics of respondents based on age, education level, occupation and marital status are presented in the frequency distribution table in table 4.1 below:

Table-4.1: Characteristics of Respondents

\begin{tabular}{|c|c|c|c|c|}
\hline \multirow[t]{2}{*}{ NO } & \multirow[t]{2}{*}{ Variable } & \multicolumn{2}{|c|}{ Frequency } & \multirow{2}{*}{$\begin{array}{l}\text { Percentage } \\
(\%)\end{array}$} \\
\hline & & & $(n=33)$ & \\
\hline \multirow[t]{7}{*}{1.} & Age & & & \\
\hline & a. $<26$ (late teens) & & 12 & $36.4 \%$ \\
\hline & b. 26-35(early adulthood) & & 5 & $15.2 \%$ \\
\hline & c. $36-45$ (late adulthood) & & 6 & $18 \%$ \\
\hline & d. 46-55(early elderly) & & 5 & $15.2 \%$ \\
\hline & e. 56-65(late elderly) & & - & - \\
\hline & f. $>66$ (seniors) & & 5 & $15.2 \%$ \\
\hline \multirow[t]{6}{*}{2.} & Education level & & & \\
\hline & a. No School & & 1 & $3.0 \%$ \\
\hline & b. SD & & 7 & $21.2 \%$ \\
\hline & c. SMP & & 6 & $18.2 \%$ \\
\hline & d. SMA & & 13 & $39.4 \%$ \\
\hline & e. College & & 6 & $18.2 \%$ \\
\hline \multirow[t]{6}{*}{3.} & Occupation & & & \\
\hline & a. Educators & & 1 & $3.0 \%$ \\
\hline & b. Self-employed & & 8 & $24.2 \%$ \\
\hline & c. Labor & & 6 & $18.2 \%$ \\
\hline & d. Not working & & 12 & $36.4 \%$ \\
\hline & e. Student & & 6 & $18.2 \%$ \\
\hline \multirow[t]{4}{*}{4.} & Marital Status & & & \\
\hline & a. Married & & 22 & $66.7 \%$ \\
\hline & b. Not Married & & 11 & $33.3 \%$ \\
\hline & Based ontable 4.1 & the & people & $(36.4 \%)$, early Adults \\
\hline
\end{tabular}


People $(15.2 \%)$ so that the majority of respondents in this study were in their late teens. Characteristics of respondents based on education level did not go to school 1 person (3.0\%), elementary school 7 people $(21.2 \%)$, junior high school 6 people $(18.2 \%)$, high school 13 people $(39.4 \%)$ and college 6 people $(18.2 \%)$ so that the majority of respondents in this study completed their education up to high school (SMA). Characteristics of respondents based on occupation 1 educator $(3.0 \%), 8$ entrepreneurs $(24.2 \%), 6$ workers (18.2\%), 12 people not working (36.4\%), and 6 students
(18.2\%) so that the respondents in this study were dominated by those who did not work. Characteristics of respondents based on marital status found 22 married $(66.7 \%)$ and 11 unmarried $(33.3 \%)$ so that respondents in this study were dominated by married people.

\section{Distribution of Respondents by Gender}

Univariate analysis of the frequency distribution of respondents by gender can be seen in table 4.2 as follows:

Table-4.2: Distribution of Respondents by Gender

\begin{tabular}{|l|l|l|l|}
\hline No & Gender & Frequency $(\mathbf{n})$ & $\%$ \\
\hline 1 & Male & 19 & 57.6 \\
\hline 2 & Female & 14 & 42.4 \\
\hline & Total & 33 & 100.0 \\
\hline
\end{tabular}

The results obtained from the medical record data of the Oesapa Public Health Center, Kupang City, obtained 19 male respondents (57.6\%) and women (42.4\%). Distribution of Respondents Based on
Length of Treatment Univariate analysis of frequency distribution of respondents based on length of treatment can be seen in table 4.3 below:

Table-4.3: Distribution of Respondents Based on Duration of Treatment

\begin{tabular}{|l|l|l|l|}
\hline No & Duration of Treatment & Frequency (n) & \% \\
\hline 1 & Intensive & 12 & 36.4 \\
\hline 2 & Continued & 21 & 63.6 \\
\hline & Total & 33 & 100,0 \\
\hline
\end{tabular}

Distribution of Respondents Based on Quality of Life Levels

The resultsobtained fromthe Univariate analysis of the medical record data of the Oesapa Public distribution of quality of life levels can be Health Center, Kupang City, obtained 12 seen in Table 4.4 following respondents who wereundergoing intensive treatment $(36.4 \%)$ and 21 people $(63.6 \%)$.

Table-4.4: Distribution of Respondents Based on Quality of Life Levels

\begin{tabular}{|c|c|c|c|c|c|c|c|}
\hline \multirow[t]{3}{*}{ Sex } & \multicolumn{5}{|c|}{ Life Quality } & \multirow{5}{*}{$\begin{array}{l}\mathbf{P} \\
1,000\end{array}$} & \multirow{5}{*}{$\begin{array}{l}\mathbf{R} \\
0.005\end{array}$} \\
\hline & $\mathrm{P}$ & oor & & $\mathrm{G}$ & ood & & \\
\hline & $\mathrm{N}$ & & $\%$ & $\mathrm{~N}$ & $\%$ & & \\
\hline Male & 15 & & 57.7 & 4 & 57.1 & & \\
\hline Female & 11 & & 42.3 & 3 & 42.9 & & \\
\hline
\end{tabular}

Table-4.5: Analysis Bivariat between Sex with Quality of Life

\begin{tabular}{|l|l|l|l|}
\hline No & Quality of Life & Frequency $(\mathbf{n})$ & $\mathbf{\%}$ \\
\hline 1 & Good & 7 & 21.2 \\
\hline 2 & Bad & 26 & 78.8 \\
\hline & Total & 33 & 100.0 \\
\hline
\end{tabular}

Bivariate analysis through Based on the table be concluded that there is no significant relationship

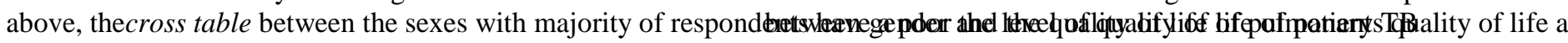

Analysis of Relationship Sex with Quality of Life of Patients Tuberculosis Bivariate analysis using Fisher's exact test was conducted to determine the relationship between sex and quality of life, the results were $\mathrm{p}=1,000$ and $\mathrm{r}=0.005$ (very weak) so that it can patients at the Oesapa Public Health Center, Kupang City.

Analysis of the Relationshipof Treatment Duration with Quality of Life of Pulmonary TB Patients. 
Table-4.6: Results of Bivariate analysis between length of treatment and Quality of Life

\begin{tabular}{|l|l|l|l|l|l|l|}
\hline \multirow{3}{*}{ Length of Treatment } & & \multicolumn{3}{|c|}{ Quality of Life } & P & r \\
\cline { 2 - 6 } & $\mathbf{P}$ & oor & Good & \multirow{2}{*}{$\mathbf{1 , 0 0 0}$} & \multirow{0}{*}{$\mathbf{0 . 4 4}$} \\
\cline { 2 - 5 } & $\mathbf{N}$ & $\mathbf{\%}$ & $\mathbf{N}$ & $\mathbf{\%}$ & & \\
\hline Incentive Phase & 10 & 38.5 & 2 & 28.6 & & \\
\hline Continuation Phase & 16 & 61.5 & 5 & 71.4 & & \\
\hline Total & 26 & 100 & 7 & 100 & & \\
\hline
\end{tabular}

Bivariate analysis through cross table between length of treatment and quality of life of pulmonary TB patients can be seen in table 4.6 below.

Bivariate analysis with Fisher's exact test was conducted to determine the relationship between length of treatment and quality of life, the results were $p$ $=1,000$ and $\mathrm{r}=0.44$ (weak) so it can be concluded that

no There is a significant relationship between the length of treatment and the quality of life of pulmonary TB patients at the Oesapa Public Health Center, Kupang City.

\section{DISCUSSION}

\section{The Relationship between Sex and Quality of Life of Pulmonary Tuberculosis Patients}

In this study, after a bivariate study between sex variables and quality of life variables indicated from 33 respondents, 19 male respondents got 15 people $(57.7 \%)$ had quality of life poor and 4 people $(57.1 \%)$ had a good quality of life, while the female respondents were 14 people, 11 people $(42.3 \%)$ had poor quality of life and 3 people (42.9\%) had good quality of life.

The results of the test using Fisher's exact test obtained $p$-value or significant value $=1,000(>=0.05)$ which means that the two variables have no relationship. The results of this study are in line with research conducted by Putri in 2017 which stated that there was no relationship between gender and quality of life of pulmonary TB patients in the working area of the Tamalate District Health Center Makassar City with avalue of $p 0.648$ [8].

The absence of a relationship between gender and the quality of life of pulmonary TB patients at the Oesapa Public Health Center is caused because the assessment of the quality of life is not only influenced by gender but can also be influenced by age and employment status. Individuals in early adulthood express higher well-being than in late adulthood so that early adulthood has a better quality of life than late adulthood. Meanwhile, respondents who enter old age have passed the time to carry out life-changing activities so that they tend to evaluate their lives more positively than when they were younger. Based on work, work is an important part that can affect the quality of life. Patients who work have more activities and have a greater opportunity to socialize with other people, so they don't think too much about their illness ${ }^{(9)}$. This is supported by the theory which states that age and employment status are predictor factors that affect the low quality of life in tuberculosis patients, especially in the physical and social domains.

\section{The Relationship of Treatment Duration with Quality of Life of Pulmonary TB Patients}

In this study, after conducting a bivariate study between the length of treatment variable and the quality of life variable indicated from 33 respondents, respondents who were undergoing the intensive phase amounted to 12 people, 10 people $(38.5 \%)$ had poor quality of life and 2 people $(28.6 \%)$ had a good quality of life, while the 21 respondents who were undergoing advanced treatment were $16(61.5 \%)$ with poor quality of life and 5 (71.4\%) with good quality of life.

The results of the test using Fisher's exact test obtained $p$-value or significant value $=1,000$ (> variables $=0$. 05) have no relationship. The which means that the two results of this study are not in line with the research conducted by Suriya in 2017 which stated that there was a significant relationship between the length of treatment and the quality of life of pulmonary TB patients [8].

The absence of a relationship between the length of treatment and the quality of life of pulmonary TB patients at the Oesapa Public Health Center is caused because the assessment of the quality of life is not only influenced by the length of treatment but can be influenced by the level of education, family social support and stress levels.

Based on the level of education a person will have a high level of confidence in behaving better if they have an educational support system. This is in line with research conducted by Louw, et al in 2012 which proved that the level of education can affect the quality of life in pulmonary tuberculosis patients. Individuals with higher levels of education have better quality of life scores than individuals with lower levels of education [9].

Family social support has also been shown to affect the quality of life of pulmonary TB patients. Families can motivate patients to undergo routine treatment, so that patients feel that their family cares for patients who are sick. In addition, family support can reduce anxiety and avoid despair, as well as reduce the fear of people around who often isolate people with pulmonary TB. The attitude of the people around such as family, friends and the community who isolate 
people with pulmonary TB will make the quality of life of people with pulmonary TB worse. This is in line with research conducted by Suriya in 2017 which proved a significant relationship between family support and the quality of life of pulmonary TB patients [8].

The factor of length of treatment that must be carried out for at least 6 months can cause frustration which can gradually become stressful for the patient so that the most influential is the level of stress or depression of a person on the quality of life of pulmonary TB patients. This is in accordance with Diamanta's research (2019) which states that there is a significant relationship between stress levels and the quality of life of pulmonary TB patients in Kupang City[10].

\section{CONCLUSION}

From the results of the study, it can be concluded as follows:

1. In this study, from 33 respondents, 19 respondents $(57.6 \%)$ were male and 14 respondents

2. $(42.4 \%)$ were female.

3. In this study, out of 33 respondents, 12 respondents $(36.4 \%)$ were undergoing the intensive phase of treatment and 21 respondents $(63.6 \%)$ were undergoing an advanced phase of treatment.

4. In this study, from 33 respondents, 7 respondents (21.2\%) had good quality of life and 26 respondents $(78.8 \%)$ had poor quality of life.

5. There is no significant relationship between gender and duration of treatment with the quality of life of pulmonary TB patients at the Oesapa Public Health Center, Kupang City.

\section{SugGeSTIONS}

\section{For Patients' Families Pay}

More attention to and support patients, especially when they are sick, so that patients have a strong desire and motivation to recover.

\section{For Puskesmas}

Can provide education and socialization to pulmonary tuberculosis patients so that patients are more able to accept their situation and try to live life as usual so that it does not have an impact on decreasing quality of life.

\section{REFERENCES}

1. Smeltzer, S.C., \& Bare, B. G. (2001). Textbook of Medical-Surgical Nursing Brunner \& suddarth 8th edn. In: Jakarta: EGC Medical Book Publisher.

2. World Health Organization. (2018). Global tuberculosis report 2018 Geneva. WHO reports.

3. Information Data Center. tuberculosis. (2018). Jakarta Ministry of Health of the Republic of Indonesia, 1-8p.

4. Sunday, D.H.K. (2018). Health Profile of East Nusa Tenggara Province 2017. Salmun E, Akoit R, Adriana K, Roja M, Saudila F, Arka E, al, Ed Kupang Health Service of East Nusa Tenggara Province, 65-67.

5. Sunday, D. H. K. (2018). Health Profile of East Nusa Tenggara Province 2017. Salmun E, Akoit R, Adriana K, Roja M, Saudila F, Arka E, al, Ed Kupang Health Service of East Nusa Tenggara Province, 65-67.

6. Rori H. No Title. (2016). The Hub of Age and Gender with Quality of Life in Heart Failure Patients at PKU Mumammadiyah Hospital Yogyakarta.

7. Khotimah, K. (2018). The relationship between the length of treatment for pulmonary tuberculosis and the level of stress in patients with pulmonary tuberculosis. J S1 Nursing Stikes Healthy Development PPNI Mojokerto.

8. Ramadhan, M. (2017). Factors Related to Quality of Life of Tuberculosis Patients in the Work Area of the Tamalate District Health Center Makassar City 2016-2017; 1-113.

9. Jannah, A. (2015). Factors Affecting Quality of Life of Pulmonary Tuberculosis Patients in the Outpatient Outpatient Clinic of Jember Pulmonary Hospital. Nursing Science Study Program, Univ. Jember.

10. Diamanta, A. (2019). Relationship between stress level and income level with quality of life of pulmonary tuberculosis patients in Kupang City. Essay.

Cite This Article: Yelsi Amaral Menina Dore et al (2022). Relationship of Gender and Treatment Long with Quality of Life of Pulmonary Tuberculosis Patients in Oesapa Public Health Center, Kupang City. EAS J Parasitol Infect Dis, 4(1), 1-5. 